\title{
Cambio Multitemporal De La Cobertura Vegetal Y Fragmentación En La Reserva Ecológica "Mache- Chindul” Ecuador
}

\author{
Jose Luis Muñoz Marcillo \\ Universidad Técnica Estatal de Quevedo \\ Docente de la Facultad de Ciencias Ambientales \\ Marcelo Andrade Mesía \\ Ministerio de Agricultura y Ganaderia,Ecuador \\ Técnico del departamento de promocion forestal \\ Betty González Osorio \\ Universidad Técnica Estatal de Quevedo,Ecuador \\ Docente de la Facultad de CienciasAmbientales
}

doi: 10.19044/esj.2016.v12n30p152 URL:http://dx.doi.org/10.19044/esj.2016.v12n30p152

\section{Abstract}

The "Mache-Chindul" -REMACH- Ecological Reserve is one of the 33 natural areas that make up the National System of Protected Areas SNAP-, administered by the Ecuadorian government through the Ministry of Environment, MAE. This ecological reserve protects one of the few remnants of tropical dry Ecuador forest, as well as a variety of endemic species of flora and fauna, many of which are endangered, the study allowed us to determine the multitemporal cover change plant (natural forest, pasture and cultivated timberline) and fragmentation of forest area between 20022012 with the implementation of programs GIS and ArcGIS Desktop 9.3 Er Mapper. Information of the study area was lifted from satellite Landsat 7 ETM (spatial resolution $30 \mathrm{~m}$ per pixel) to the same as a composition of pseudo color (RGB-431) and a classification applied supervised using the method of Minimum Distance. The ecological reserve has an area of 53,662 hectares of natural forest, equivalent to $44.7 \%$ of total area, $23.1 \%$ is regeneration or recovery of natural forest with an area of 27,707 hectares; the natural forest has undergone several interventions, considering the most affected and the peripheral area south of the rivet end, fragmentation was of 38,632 was equivalent to $32.2 \%$ of the total area of the reserve, in the category of cultivated grass product the increase of the agricultural frontier and decreasing natural forest cover from the illegal extraction of wood, also the pressure from timber companies and colonization fronts, concerning the population index this has decreased from 5.71 to $5.39 \mathrm{hab} / \mathrm{km}^{2}$. 
Keywords: Multitemporal change, vegetation cover, satellite images, remote sensing, image composition

\section{Resumen}

La Reserva Ecológica "Mache-Chindul” -REMACH- es una de las 33 áreas naturales que conforman el Sistema Nacional de Áreas Protegidas SNAP-, administrada por el Estado ecuatoriano a través del Ministerio del Ambiente, MAE. Esta reserva ecológica protege uno de los pocos remanentes del bosque húmedo y seco tropical de Ecuador así como una gran variedad de especies endémicas de flora y fauna, muchas de las cuales están en peligro de extinción, el estudio permitió determinar el cambio multitemporal de la cobertura vegetal (bosque natural, pasto cultivado y vegetación arbórea)y la fragmentación del área boscosa entre los años 20022012con la aplicación de los programas de Sistemas de Información Geográfica ArcGis Desktop 9.3 y Er Mapper. Se levantó información del área de estudio a partir de imágenes satelitales Landsat 7 ETM(resolución espacial 30m por pixel) a las mismas que se aplicaron una composición de pseudo color (RGB-431) y una clasificación supervisada empleando el método de Mínima Distancia.La reserva ecológica posee una superficie de 53.662 ha de bosque natural, que equivale al 44,7 \% de área total, el 23,1\% corresponde a regeneración o recuperación del bosque natural con una superficie de 27.707 ha, el bosque natural ha sufrido varias intervenciones, considerándose las más afectadas el área periférica y el extremo sur de la REMACH, la fragmentación ha sido de 38.632 ha equivalente al 32,2 \% del área total de la reserva, en la categoría de pasto cultivado producto del aumento de la frontera agrícola y a la disminución de la cobertura de bosque natural producto de la extracción ilegal de la madera, además, la presión que ejercen las empresas madereras y los frentes de colonización, referente al índice poblacional este ha decrecido de 5,71 a 5,39 hab $/ \mathrm{km}^{2}$.

Palabras claves: Cambio multitemporal, cobertura vegetal, imágenes satelitales, percepción remota, composición de imágenes

\section{Introducción}

En las áreas protegidas, la conversión de los hábitats naturales es la causa más grande de pérdida de diversidad biológica, funciones ecológicas y alteraciones del ciclo hidrológico, el balance entre hábitat y paisaje humano podría determinar el futuro éxito de la conservación de la diversidad biológica en grandes áreas del planeta, por lo que es importante mapear y cuantificar el grado de conversión del hábitat natural al perturbado o dominado por el hombre(MAE 2015). 
La cobertura vegetal llamados cuerpos naturales o artificiales cubren la superficie del suelo, éstos pueden originarse en ambientes naturales como resultado de la evolución ecológica (bosques, sábanas, lagunas, etc.), a partir de ambientes artificiales creados y mantenidos por el hombre (cultivos, represas, ciudades, etc.).

La Reserva Ecológica “Mache-Chindul” -REMACH- es una de las 33 áreas naturales que conforman el Sistema Nacional de Áreas Protegidas SNAP-, administrada por el Estado ecuatoriano a través del Ministerio del Ambiente -MAE-, cubre una extensión de 120,002 ha, en esta se protege uno de los pocos remanentes del bosque húmedo y seco tropical del Ecuador, así como una gran variedad de especies endémicas de flora y fauna, muchas de las cuales están en peligro de extinción.

Este estudio permite obtener mapas de los cambios de cobertura vegetal y fragmentación del hábitat. A partir de ellos, se pudieron conocer los diferentes tipos de problemas del ecosistema, esto es: reducción del hábitat para las especies ocasionados por factores humanos, ampliación de la frontera agrícola, explotación irracional del bosque natural, eliminación de la flora y fauna endémica; factores que permitieron discutir alternativas de solución para las áreas intervenidas dentro de la reserva.

\section{Metodología}

\section{Localización y caracterización del área de estudio}

La REMACH, es una de las 33 áreas naturales que conforman el Sistema Nacional de Áreas Protegidas -SNAP-, administrado por el Estado ecuatoriano a través del Ministerio del Ambiente -MAE-. Cubre una extensión de 120.002 ha entre los cantones Quinindé, Atacames, Esmeraldas y Muisne, en la provincia de Esmeraldas; y el cantón Pedernales en la provincia de Manabí. La REMACH se extiende desde los $200 \mathrm{msnm}$ en el sector occidental, hasta cerca de los $800 \mathrm{msnm}$ en las colinas orientales. En esta región, la REMACH protege uno de los pocos remanentes de bosques húmedos y secos tropicales del Ecuador, así como una gran variedad de especies endémicas de flora y fauna, muchas de las cuales en peligro de extinción. Este es el espacio de vida de poblaciones ancestrales de la nacionalidad Chachi, pueblo afroecuatoriano y colonos provenientes de las provincias de Manabí, Loja y Los Ríos, principalmente.

\section{Recopilación de la información de partida}

Larecopilación de imágenes Landsat 7 ETMdela reserva ecológica REMACH, ubicada entre las provincias de Esmeraldas y Manabí se la obtuvo a través del Instituto Espacial Ecuatoriano. Las principales características de las imágenes son:

$\checkmark$ Referencia espacial: WGS84 UTM Zona 17N 
$\checkmark$ Tamaño del pixel (m): $30 \times 30$

$\checkmark$ Formato: Geotiff

$\checkmark$ Número de bandas (6): 1, 2, 3, 4, 5, 7

\section{Elaboración de mapas individuales de distintas coberturas por años}

El procesamiento de las imágenes Landsat 7 ETMse lo realizó en el programa de Sistemas de Información Geográfica ArcGis Desktop versión 9.3 y Er Mapper.El proceso empleado para determinar las coberturas del suelo de acuerdo a los años de interés en la REMACH se explica a continuación:

Las imágenes Landsat 7 ETM del área de estudio correspondientes a los años 2002, 2005, 2008 y 2012 ortorectificadas y con eliminaciones de distorsiones atmosféricas fueron tratadas con el procesador de imágenes ER Mapper que permitió realizar una composición de bandas en la combinación 431( RGB) logrando discriminar patrones homogéneos de coberturas del suelo, entre ellas la cobertura vegetal y otras categorías según la condición de las diferentes imágenes de satélite en donde se incluyó área de nubes, sombras de nubes y bandeamiento de las imágenes de satélite. Seguidamente para establecer los sitios de entrenamiento se partió del inventario cartográfico del proyecto INFOPLAN del Ministerio de Agricultura y Ganadería que incluyó áreas de camaroneras, bosque natural, pasto cultivado y vegetación arbustiva, aplicando finalmente la clasificación supervisada de la REMACH mediante el método de Mínima Distancia. Los usos del suelo obtenidos fueron validados mediante la aplicación de la matriz de confusión.

Cabe destacar que de manera complementaria se tomaron puntos de control en campo, los que se utilizaron para contrastar con imágenes satelitales previamente seleccionadas, para de esta forma establecer en la REMACH los cambios de la cobertura vegetal y niveles de fragmentación del bosque natural.

\section{Elaboración del mapa de fragmentación del bosque natural}

El análisis del cambio multitemporal de la cobertura vegetal se lo realizó a través del programa ArcGis9.3y su aplicaciónArcMap, obteniendo el mapa de fragmentación de la vegetación natural, proceso que se explica a continuación.

Una vez definidos los usos del suelo en el área de estudio producto de la clasificación supervisada de las imágenes de satélite se reclasificaran los valores de los pixeles de las matricesde cada una de las cuatro imágenes de satélite (años 2002, 2005, 2008, y 2012) considerando el trabajo reclasificación de capas digitales de información en un entorno SIG realizado por (Muñoz et al., 2014) para posteriormente ser sometidas a un cálculo matemático de adición con ayuda de la función raster calculator que 
simplificala coincidencia espacial que existe entre las coberturas para los años en estudio, derivando en una matriz raster con una gradiente adimensional de entre 1 a 4 , en donde las áreas con valor 4 corresponderían a sectores boscosos de la REMACH que no han sufrido intervención en el tiempo mientras que las áreas con valores menores indican un grado de intervención de las cubiertas boscosas a través del tiempo, de tal manera que las áreas con valores de 1 y 2se consideran intervenidas mientras que las de valor 3 corresponden a área de regeneración.

\section{Resultadosy discusión}

\section{Cambios en la cobertura vegetal}

En la Figura 1, aparecen con claridad las coberturas vegetales existentes en la Reserva Ecológica "Mache-Chindul" -REMACH- para el año 2002. En la imagen se muestra la cobertura de bosque natural con una superficie de 48.046 ha que representa el $40 \%$ del área total de la reserva. Se identifica en la imagen la cobertura de vegetación arbustiva con una superficie de 47.263 ha que representa el 39,4 \% del área total de la reserva y, finalmente, se puede ver la cobertura de pasto cultivado con una superficie de 9.550 ha que representan el $8 \%$ del área total de la reserva.

En la Figura 2, aparecen con claridad las coberturas vegetales existentes en la Reserva Ecológica "Mache-Chindul" REMACH para el año 2005. En la imagen se muestra la cobertura de bosque natural con una superficie de 49.895 ha que representa el 41,6 \% del área total de la reserva. Se identifica en la imagen la cobertura de vegetación arbustiva con una superficie de 17.194 ha que representa el 14,3 \% del área total de la reserva y finalmente se puede ver la cobertura de pasto cultivado con una superficie de 27.299 ha que representan el 22,7 \% del área total de la reserva.

En la Figura 3, aparecen con claridad las coberturas vegetales existentes en la Reserva Ecológica "Mache-Chindul" REMACH para el año2010. En la imagen se muestra la cobertura de bosque natural con una superficie de 37.772 ha que representa el 31,5 \% del área total de la reserva. Se identifica en la imagen la cobertura de vegetación arbustiva con una superficie de 17.016 ha que representa el 14,2 \% del área total de la reserva y finalmente se puede ver la cobertura de pasto cultivado con una superficie de 43.635 ha que representan el 36,4 \% del área total de la reserva.

En la Figura 4,se muestran las coberturas vegetales existentes en la Reserva Ecológica "Mache-Chindul” REMACH para el año 2012. En la imagen se muestra la cobertura de bosque natural con una superficie de 38.342 ha que representa el 32 \% del área total de la reserva. Se identifica en la imagen la cobertura de vegetación arbustiva con una superficie de 28.284 ha que representa el 23,6 \% del área total de la reserva y finalmente se puede ver la cobertura de pasto cultivado con una superficie de 30.169 ha que 
representan el 25,1 \% del área total de la reserva.Esta fragmentación es similar a los resultado obtenidos en estudio como el Parque Nacional Yacambú en Venezuela con una superficie del $20 \%$ del área total de la REMACH perdió 508,51 ha de la superficie ocupada por coberturas naturales y ganó 475,29 ha dedicadas a la actividad agrícola. El área total de cambios registrada fue de 3,88 \%, esta pérdida es alentadora en comparación con los obtenidos en otros parquesvenezolanos como el Juan Pablo Peñalosa y el Morrocoy donde el cambio de la superficie fue del $16 \%$ al $9 \%$ respectivamente (Molina y Anderson, 2013)

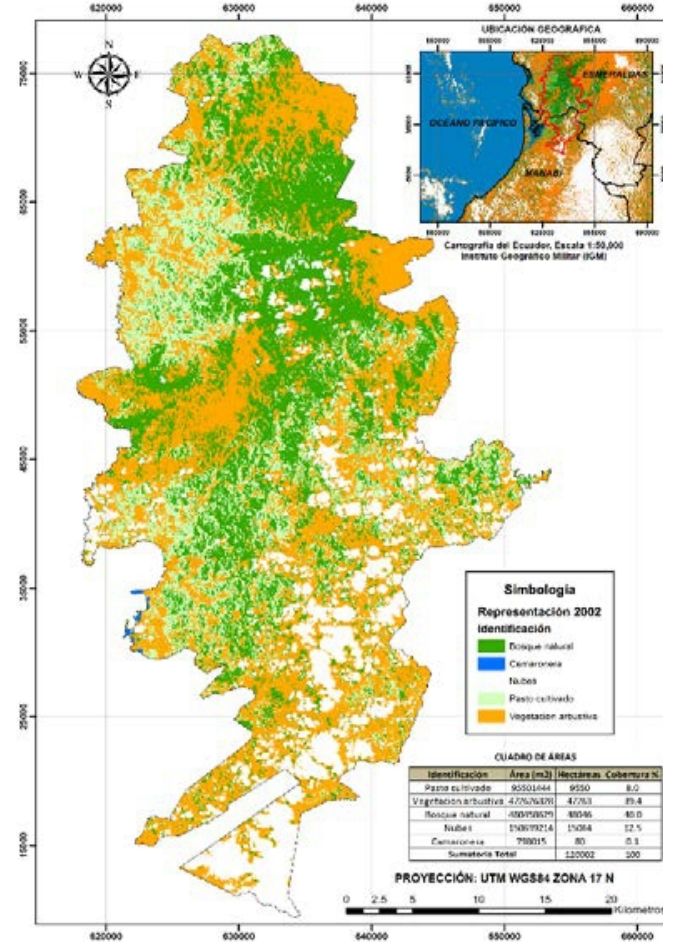

Figura 1. Cobertura vegetal de la REMACH. Ecuador. 2002

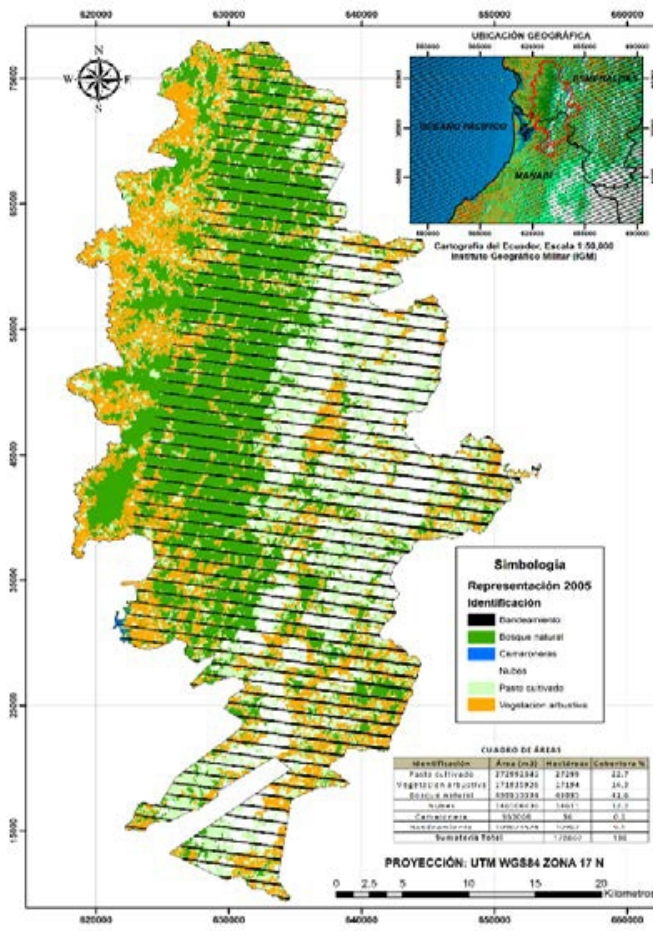

Figura 2. Cobertura vegetal de la REMACH. Ecuador. 2005 


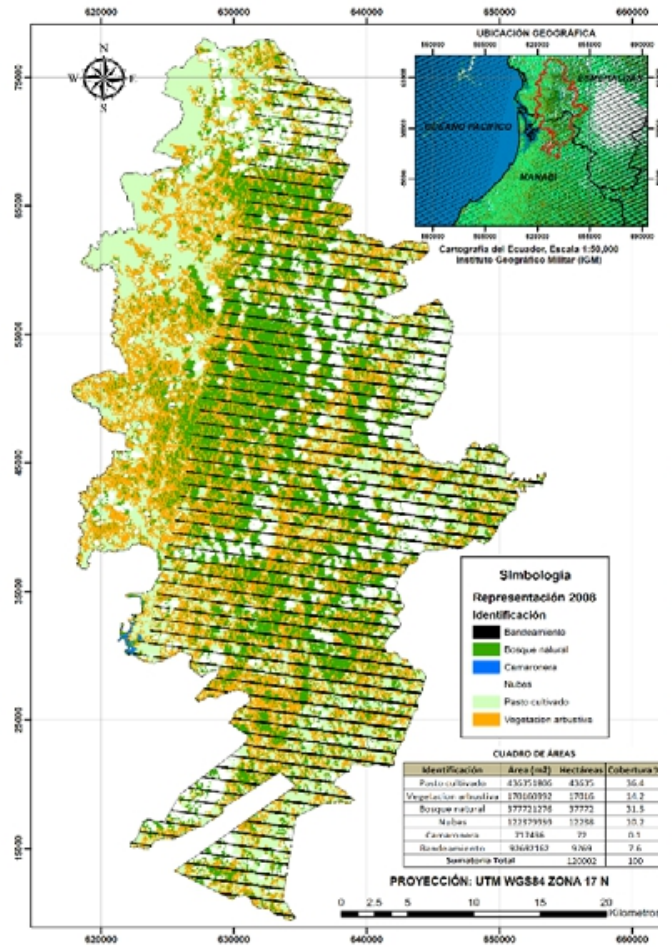

Figura 3. Cobertura vegetal de la REMACH. Ecuador. 2010

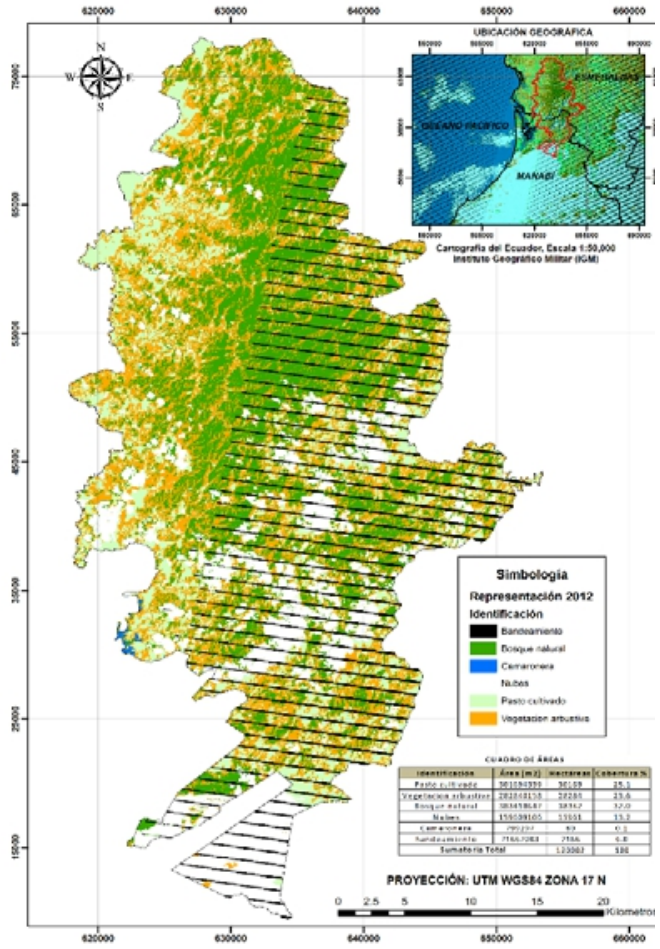

Figura 4. Cobertura vegetal de la REMACH. Ecuador. 2012

La aplicación de la matriz de confusión en el presente estudio para evaluar la exactitud de la clasificación de lasimágenes de satélite resultó en un valor de 0,3288 (Tabla 1), considerado un porcentaje aceptable de error al contrastar las coberturas reales y obtenidas por clasificación supervisada dentro de la REMACH (Muñoz et. al., 2016) mientras que el coeficiente de Kappa en un valor de 0,4895 indica un alto valor de concordancia entre las matrices contrastadas.

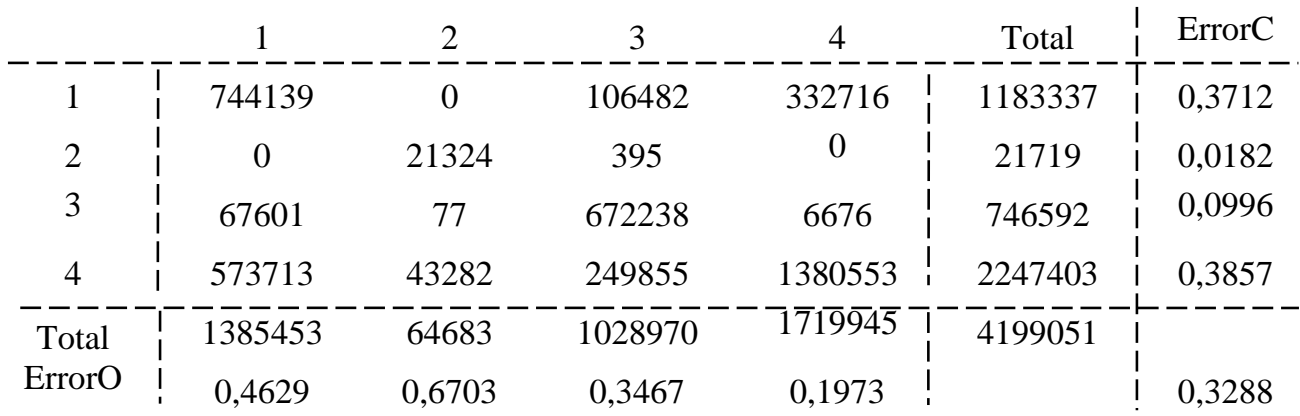

Tabla 1. Matriz de confusión 


\section{Niveles de fragmentación}

En la Figura 5, aparecen con claridad los niveles de fragmentación de las coberturas vegetales existentes en REMACH para el periodo 2002-2012. En la imagen se da la fragmentación o permanencia de las coberturas definidas a través de los siguientes tipos: áreas intervenidas, áreas de regeneración y áreas de bosque natural.

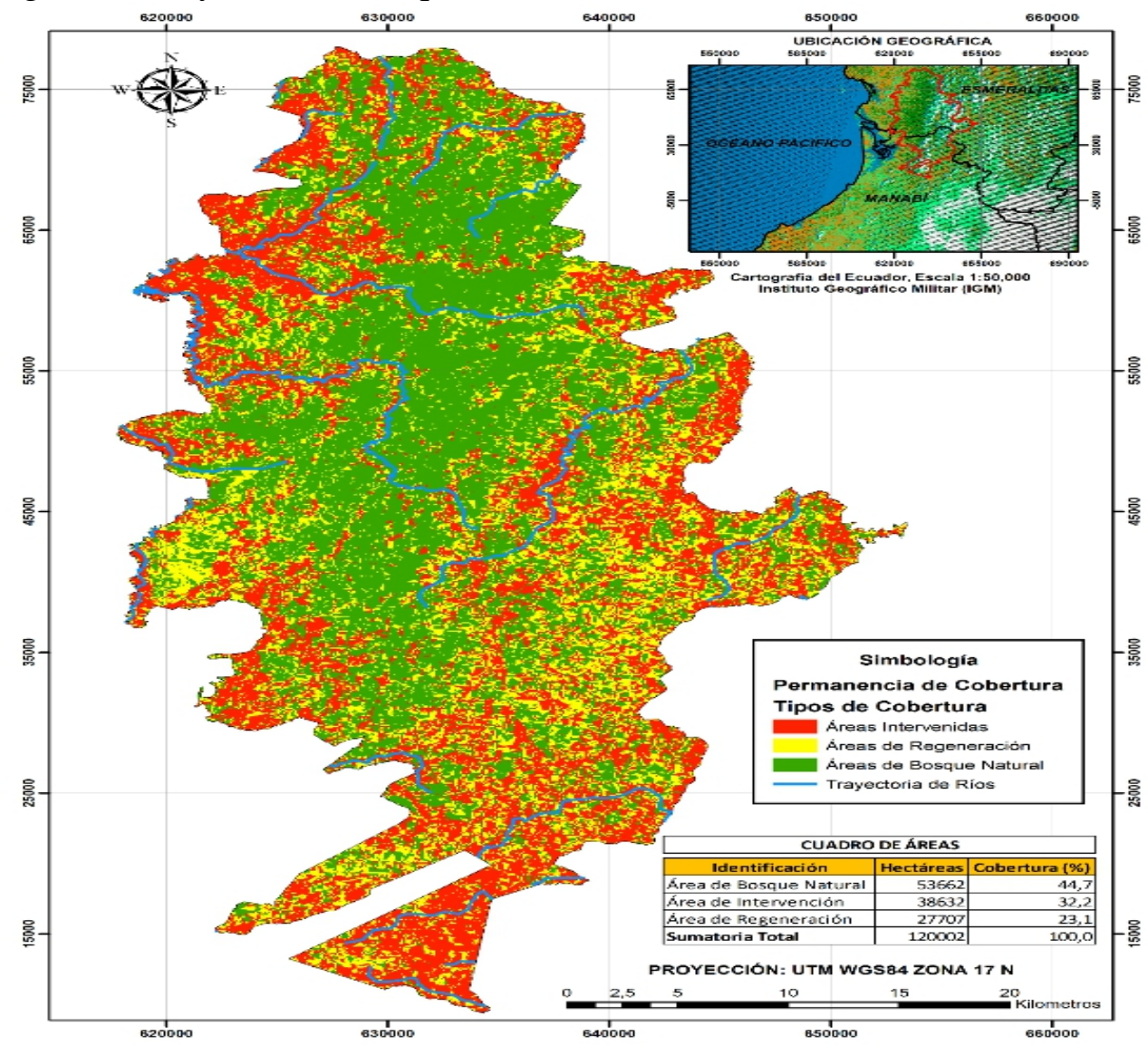

Figura 5. Permanencia de las coberturas vegetales dentro de la REMACH, Ecuador, periodo 2002-2012

Esta cobertura posee una superficie de 38.362 ha que corresponde al $32,2 \%$ del área total de la reserva. Se encuentran ubicadas en las zonas periféricas de la reserva, las zonas más afectadas se ubican geográficamente en la parte noroeste y en el extremo sureste ingresando hasta la parte central de la misma, aproximadamente unos $15 \mathrm{~km}$.

\section{Áreas de regeneración}

La cobertura cuenta con una superficie 27.707 ha que equivale al 23,1 \% del área total de la reserva. Se ubican desde la zona central hacia la 
periferia de la reserva, una zona en proceso de regeneración significativa se encuentra ubicada geográficamente en la zona central oeste y otra de igual condiciones en el cuadrante suroeste de la misma.

\section{Áreas de bosque natural}

El principio en el que se basan los métodos de clasificación no supervisada de imágenes de satélite multiespectrales pierde precisión a la luz de que la intervención humana se torna imprescindible para este tipo de procesos o que al menos se debe integrar información adicional que permitan tomar decisiones al algoritmo sobre la posibilidad de que exista una cobertura en un determinado sitio, basados en condiciones como el relieve, humedad relativa, frecuencia de lluvias, etc. (Gutiérrez, William, \& Bedoya, 2005).

En los periodos 2002 al 2010, la categoría de pasto cultivado presenta un crecimiento de 9.550 a 43.635 ha, lo que implicó un incremento de 7,96 al $36,36 \%$ de la superficie total de la reserva (ver Tabla 2); debido a que la Reserva Ecológica "Mache-Chindul” fue establecida con un gran número de centros poblados que se encontraban ya al interior de la misma y otros en proceso de consolidación, en consecuencia y con el pasar del tiempo se originó una progresiva ampliación de la frontera agrícola por la gran demanda de granos y presencia humana en el sitio.En un período de diez años la cobertura de la tierra en el parque natural Santuario de flora y fauna Los Flamencos de Colombia presentaron cambios reportados en un $41 \%$. (Pastos enmalezados o en rastrojados que se transforman en un 100 \% y de pastos con espacios naturales que sólo conserva el 11 \% del área que cubría). Las coberturas que no presentan cambios son Bosque de galería, Bosque de Mangle, Pastoslimpios, Playas arenales y dunas y Zonas pantanosas, los mismo que no registraron cambios superiores a 5 ha, dado que ésta es la unidad mínima de reporte de cambio (Corredor, Cárdenas y Ordóñez, 2011).

En relación a la categoría de pasto cultivado, del año 2002 hasta el año 2010, se da un crecimiento de 9.550 a 43.635 ha, ver Tabla 2, lo que implicó que se dedicaron el 36,40 \% en relación al 100 \% de la extensión total de la reserva, pero para el año 2012 disminuye y se ubica un 25,1 \% debido a la emigración de los comuneros y colonos por el impacto de la crisis económica neoliberal y también porque la ganadería no constituía un incentivo económico rentable.

El análisis de la fragmentación del 2010 al 2011 del paisaje en Cuchillas de la Zarca, México (De León, Álvarez, Martínez, 2014) permitió definir con claridad seis clases de coberturas del suelo: pastizal, matorral, desértico micrófilo, bosques de encino-pino, áreas de chaparral y cuerpos de agua 4,6 \%. Los datos evaluados durante el periodo mostraron valores altos de exactitud, el valor relativamente más bajo lo presentó la clase de pastizal, 
mientras que el valor más alto lo obtuvo la clase de cuerpos de agua, disminuyendo un poco en el 2009 e incrementando para 2010 y 2012.

En los periodos de 2002 al 2012, la categoría de bosque natural presenta una disminución de 48.046 a 38.342 ha, lo que implicó un decremento de 39,39 al 23,57 \% de la extensión total de la reserva, ver Tabla 2, producto de la deforestación y otras actividades antropogénicas. Además. la presión que ejercen las empresas madereras en el área de influencia de la reserva y los frentes de colonización que se están formando, amenazan no sólo la conservación de la integridad ecológica del bosque natural, sino también la preservación de los recursos culturales en la REMACH. En un estudio de la fragmentación del bosque nativo en la cuenca del río Aysén (Patagonia-Chile) se cuantifico la pérdida y segmentación del bosque nativo debido principalmente al uso antrópico del fuego, destacando la gran utilidad prestada por el uso de los Sistema de Información Geográfica (SIG) como herramientas fundamentales en la reconstrucción del paisaje boscoso de Aysén (Armesto, 1997; Bizama et. al. 2011)

La fragmentación forestal en el centro-sur de Chile se encuentra dominada por fragmentos de bosque nativo de muy bajo tamaño (más del 60 \% de tamaño inferior a $1 \mathrm{ha}$ ), lo cual representa uno de los principales argumentos para afirmar que estos bosques se encuentran sometidos a un fuerte proceso defragmentación (Armenteras, 2003; Altamirano 2007)

Tabla 2. Análisis del cambio de la cobertura vegetal en la Reserva Ecológica Mache-

Chindul durante el periodo 2002-2012

\begin{tabular}{|c|c|c|c|c|c|c|c|c|}
\hline \multirow{3}{*}{ Descripción } & \multicolumn{8}{|c|}{ Años de Estudio } \\
\hline & \multicolumn{2}{|c|}{2002} & \multicolumn{2}{|c|}{2005} & \multicolumn{2}{|c|}{2010} & \multicolumn{2}{|c|}{2012} \\
\hline & ha & $\%$ & ha & $\%$ & ha & $\%$ & ha & $\%$ \\
\hline Pasto cultivado* & 9.550 & 7,96 & 27.299 & 22,75 & 43.635 & 36,36 & 30.169 & 25,14 \\
\hline Vegetación arbustiva & 47.263 & 39,39 & 17.194 & 14,33 & 17.016 & 14,18 & 28.284 & 23,57 \\
\hline Bosque natural** & 48.046 & 40,04 & 49.895 & 41,58 & 37.772 & 31,48 & 38.342 & 31,95 \\
\hline Camaronera & 80 & 0,07 & 96 & 0,08 & 72 & 0,06 & 80 & 0,07 \\
\hline Nubes/Bandeamiento & 15.063 & 12,55 & 25.518 & 21,26 & 21.507 & 17,92 & 23.127 & 19,27 \\
\hline TOTAL & 120.002 & 100 & 120.002 & 100 & 120.002 & 100 & 120.002 & 100 \\
\hline & & $\begin{array}{l}\text { ncreme } \\
* * \text { Extr }\end{array}$ & $\begin{array}{l}\text { o de la fr } \\
\text { ción ileg }\end{array}$ & $\begin{array}{l}\text { tera ag } \\
\text { de ma }\end{array}$ & $\begin{array}{l}\text { cola. } \\
\text { ra }\end{array}$ & & & \\
\hline
\end{tabular}

\section{Contexto social y humano dentro de la Reserva Ecológica "Mache- Chindul” REMACH}

En la Tabla 3, se presentan los resultados obtenidos en el Censo de Población y Vivienda realizado en el año 2010.

En la Reserva Ecológica "Mache-Chindul” -REMACH, se ha dado un ligero proceso de decrecimiento poblacional. Se estimó que para el año 2010 el número de pobladores dentro de la reserva fue de 6.466 habitantes. 
Si relacionamos este valor con la extensión de la reserva $\left(1.200,02 \mathrm{~km}^{2}\right)$ se concluyó que la densidad poblacional para ese año fue de 5,39 habitantes/ $\mathrm{km}^{2}$. Esto confirmó una leve tendencia decreciente, puesto que, en el estudio de alternativas de manejo de 1994 se estableció una tasa de 5,71 habitantes/ $\mathrm{km}^{2}$. (Alianza REMACH/MAE, 2014).

Tabla3. Población aproximada dentro de la Reserva Ecológica "Mache-Chindul”. (Alianza REMACH, 2012)

\begin{tabular}{|c|c|c|c|}
\hline Cantón & Parroquias & $\begin{array}{l}\text { Habitantes dentro de la } \\
\text { Reserva, plan de manejo }\end{array}$ & $\begin{array}{l}\text { Porcentaje de } \\
\text { la población } \\
\text { dentro de la } \\
\text { reserva }\end{array}$ \\
\hline Atacames & La Unión & 300 & 4,64 \\
\hline Esmeraldas & Carlos Concha & 153 & 2,37 \\
\hline Quinindé & Cube & $\begin{array}{l}1.556 \text { (380 chachis de } \\
\text { Chorrera Grande) }\end{array}$ & 24,06 \\
\hline Muisne & $\begin{array}{l}\text { Muisne, Salima, } \\
\text { Daule, San Gregorio, } \\
\text { Chamanga }\end{array}$ & $\begin{array}{l}2.523 \text { (730 chachis de Balzar } \\
\text { y Salvador) }\end{array}$ & 39,02 \\
\hline Pedernales & & 1.934 & 29,91 \\
\hline TOTAL & & 6.466 & 100.00 \\
\hline
\end{tabular}

Fuente: Los Autores

\section{Conclusion}

Las técnicas de teledetección aplicadas al estudio de la dinámica de la cobertura boscosa del suelo nos permiten determinar con alta precisión los tipos y la extensión de coberturas existentes. La limitante de las técnicas de análisis multitemporal al estudio de la cobertura forestal es la poca disponibilidad de imágenes de satélite de gran resolución espacial así como su limitada funcionalidad causada por los elevados porcentajes de nubosidad como consecuencia de condiciones atmosféricas adversas presentes permanentemente en ciertas extensiones superficiales.La clasificación supervisada de imágenes de satélite aplicando el método de mínima distancias probó ser un método muy eficiente para la analizar la evolución de la densidad de áreas boscosas presentes en décadas pasadas dentro de la reserva ecológica Mache Chindul (REMACH).

La metodología empleada para el presente estudio centrada en la interpretación y aplicación de información de sensores remotos pudiera extrapolarse a escala de todo el país considerando como factor importante la validación con indicadores medidos en terreno.

La cobertura de bosque natural dentro de la Reserva Ecológica "Mache-Chindul" -REMACH, es de 53.662 hectáreas, que equivale al 44,7 \% del área total de la reserva; focalizándose en la zona central, extendiéndose en mayor proporción hacia el Norte y en menor medida hacia el Sur de la reserva.Por otra parte,las áreas de regeneración o recuperación 
del bosque natural es de 27.707 ha equivalente al 23,1 \% de área total de la reserva.

La REMACH ha sufrido intervenciones a lo largo del tiempo, llegando a convertirse el área periférica como la más afectada; focalizándose en los sectores noroeste, sureste hasta la zona central de la misma. Siendo así que las áreas que sufrieron un cambio total tienen una superficie de 38.362 ha, equivalente al 32,2 \% del área total de la reserva.

\section{References:}

1. Altamirano, A., Echeverría, C., \& Lara, A. (2007). Efecto de la fragmentación forestal sobre la estructura vegetacional de las poblaciones amenazadas de Legrandia concinna (Myrtaceae) del centro-sur de Chile. Revista Chilena de Historia Natural 80: 27-42

2. Armenteras, D., Gast F., \& Villareal, H. (2003). Andean forest fragmentation and the representativeness of protected natural areas in the eastern Andes, Colombia. Biological Conservation 113: 245-256

3. ARMESTO, A.; LEÓN, P. y ARROYO, M. (1997). Los bosques templados del sur de Chile y Argentina: una isla biogeográfica. En: ARMESTO, A.; VILLAGRÁN, J. y ARROYO, M. C. (eds.). Ecología de los Bosques Nativos de Chile. Santiago: Editorial Universitaria. 71-92.

4. Asamblea Nacional. 2010. Código Orgánico de Organización Territorial, Autonomía y Descentralización, Reg. Oficial. No 303

5. Corredor, L., Cárdenas, E., \& Ordóñez, J. (2011). Aplicación de la metodología corine land cover en la determinación de los cambios de cobertura en el parque natural los flamencos. Ciencia e Ingeniería Neogranadina, vol. 21-2, pp. 153 - 167

6. Bizama, G., Torrejón, F., Aguayo, M., María, D., \& Echeverría, C. (2011). Pérdida y fragmentación del bosque nativo en la cuenca del río Aysén (Patagonia-Chile) durante el siglo XX ${ }^{1}$. Revista de Geografía Norte Grande, 49: 125-138

7. De León G., Álvarez, G., Martínez J. (2014). Aplicación de sensores remotos en el análisis de la fragmentación del paisaje en Cuchillas de la Zarca , México Application of remote sensing in the analysis of landscape fragmentation in Cuchillas de la Zarca, Mexico. Investigaciones Geográficas: Boletín Del Instituto de Geografía, 2014(84), 42-53. http://doi.org/10.14350/rig.36568

8. Gutiérrez, M. A., William, J., \& Bedoya, B. (n.d.). Clasificación no supervisada de coberturas vegetales sobre imágenes digitales de sensores remotos : “LANDSAT 7 ETM - ETM + .”, Rev. Fac. Nal. Agr. Medellín. Vol.58, No. 1. pp. 2611-2634 
9. Ministerio del Ambiente de Ecuador 2015. Quinto Informe Nacional para el Convenio sobre la Diversidad Biológica. Quito Ecuador. 296p.

10. Ministerio del Ambiente 2011. Mapa de deforestación histórica en el Ecuador continental (en línea). Consultado 06/enero/2014. Disponible

en: http://www.ambiente.gob.ec/sites/default/files/users/mponce/TasasDe forestacionEcuador.Ver_.03.05.11.pdf

11. Ministerio del Ambiente 2014. Plan de Manejo de la Reserva "Mache-Chindul" (REMACH). Consultado: 02 de diciembre de 2015. Disponible en: http://www.ambiente.gob.ec

12. Molina, Gladyz Z., \&Albarran, Anderson J. (2013). Análisis multitemporal y de la estructura horizontal de la cobertura de la tierra: Parque Nacional Yacambú, estado Lara, Venezuela. Cuadernos de Geografía - Revista Colombiana de Geografía, 22(1), 25-40. RetrievedAugust 09, 2014 , fromhttp://www.scielo.org.co/scielo.php?script=sci_arttext\&pid=S01 21-215X2013000100003\&lng=en\&tlng=es

13. Muñoz, J., Cuásquer, E., Moncayo, O. \& Delgado, D. (2016). Aplicación de percepción remota para la detección de cambios en la cobertura boscosa de la reserva ecológica Mache-Chindul. Revista La Técnica, 16, 76 - 93.

14. Muñoz, J., Morante, J., \& Miranda, P. (2014). Erosión potencial por reconversión productiva en subcuenca Llay- Llay, Chile aplicación de unidades de respuesta a la erosión. Revista Ciencia y Tecnología, 8,37 - 47.

15. Gutiérrez, M. A., William, J., \& Bedoya, B. (n.d.). CLASIFICACIÓN NO SUPERVISADA DE COBERTURAS VEGETALES SOBRE IMÁGENES DIGITALES DE SENSORES REMOTOS : “LANDSAT 7 ETM- ETM + .”, Rev. Fac. Nal. Agr. Medellín. Vol.58, No. 1. pp. 2611-2634.

16. Bizama, G., Torrejón, F., Aguayo, M., María, D., \& Echeverría, C. (2011). Pérdida y fragmentación del bosque nativo en la cuenca del río Aysén (Patagonia-Chile) durante el siglo XX 1, 138, 125-138.

17. Corredor, L., Cárdenas, E., \&Ordóñez, J. (2011). Aplicación de la metodología corinelandcover en la determinación de los cambios de cobertura en el parque natural los flamencos. Ciencia e Ingeniería Neogranadina, vol. 21-2, pp. 153 - 167

18. Chuvieco, E. 2008. Teledetección Ambiental. La observación de la Tierra desde el espacio, Barcelona, Ed. Ariel Ciencia, 3a ed., 594 pp.

19. Chuvieco, E. y Huete, A. 2010. Fundamentals of satellite remote sensing, Boca Raton, 436 pp. 
20. Ministerio del Ambiente. Sep. 2010. Texto unificado de la Legislación Ambiental Secundaria. Disponible en www.ambiente.gob.ec

21. Rivas, J. 2011. Elaboración de cartografía integrada de peligros asociados, aplicación a la cuenca del arroyo Jabonero. MálagaEspaña. 106pp.

22. Ruiz, V., Savé, R., Herrera, A. 2013. Análisis multitemporal del cambio de uso del suelo, en el Paisaje Terrestre Protegido MiraflorMoropotente Nicaragua, 1993-2011. Ecosistemas 22(3):117123. Doi.: 10.7818/ECOS.2013.22-3.16. 